\title{
Structural Model for the Effects of Perceived Indoor Work Environment on Sick Building Syndrome and Stress
}

\author{
Nor Hazana Abdullah ${ }^{1}$, Nor Aziati Abdul Hamid ${ }^{1}$, Muhamad Shahrul Amirul Shaif ${ }^{2}$, Alina Shamsuddin ${ }^{1}$, Eta Wahab ${ }^{1}$ \\ ${ }^{1}$ Faculty of Technology Management, UTHM, Malaysia \\ ${ }^{2}$ Ye Chiu Metal Smelting, Johor, Malaysia
}

\begin{abstract}
Sick Building syndrome (SBS) and stress have a prevalent influence on organizational productivity and competitiveness. Unhealthy employees not only tend to have high medical leaves but also low productivity due to ailments and discomforts. Studies that investigate the effects of indoor work environment on Sick Building Syndrome (SBS) have yielded mixed results while their effect on stress has not been empirically established. Furthermore, studies that simultaneously investigate both SBS and stress are almost non-existent. Thus, this study aimed to study the effects of perceived indoor work environment on SBS and stress and the link between SBS and stress. A crosssectional survey participated by 598 employees from various industries was conducted from September to October 2015. Data were analyzed using Partial Least Square Structural Equation Modeling (PLS-SEM) to assess both the measurement model and the path structure. The results suggest that indoor work environment has significant yet the weak effect on SBS while it has no effect on stress. However, SBS has a strong significant relationship with stress. The implication of this study on the importance of conducive indoor work environment is discussed with suggestions for future studies.
\end{abstract}

\section{Introduction}

Sick Building syndrome (SBS) refers to a constellation of symptoms experienced by employees who are working in the structural confinement of buildings. Such symptoms include a headache, nose and throat irritation, dry cough and itchiness without known causes/illnesses [1]. Stress, on the other hand, refers to "mechanism whereby the human body attempts to adapt to the environment". Failure to be adaptive to stress has dire consequences at individual and organizational levels [2]. Studies have shown that SBS and stress not only has an impact on productivity [3] [4], but also on job satisfaction [5] [6] and other organizational outcomes. In a nutshell, SBS and stress have a prevalent influence on organizational effectiveness. Unhealthy employees not only tend to have high medical leaves but also low productivity and commitment to work due to ailments and discomforts.

Among predictors claimed to affect SBS and stress is the indoor work environment [7]. As most employees spend the majority of their time at the workplace, the indoor work environment might not only influences their physical wellbeing but also their psychological states. Kogi [8] found that combined environmental exposure and indoor air quality are one of the top emerging issues of occupational and environmental health among fifteen Asian-Pacific countries being surveyed. Moreover, temperature, particularly heat, is ranked first as the most important occupational health problem which is aligned Hole and
Pande's finding [9]. Statistics from the Social Security Organizations of Malaysia also shows an upward trend where the number of occupational diseases has increased from 194 cases in 2005 to 3002 cases in year 2014.

Studies that investigate the effects of indoor work environment on Sick Building Syndrome (SBS) have yielded mixed results while their effect on stress has not been firmly established. Moreover, majority of these studies are no longer recent and their findings need to be reaffirmed. Furthermore, studies that simultaneously investigate both SBS and stress are almost non-existent. Consequently, this study aimed to study the effects of perceived indoor work environment on SBS and stress and the link between SBS and stress using a more robust analysis via the Structural Equation Modeling.

\section{Literature review}

Discussion on related works of Indoor Work Environment, Sick Building Syndrome, and Stress is partitioned in subsequent sub-sections to reflect corresponding hypotheses formulation.

\subsection{Indoor work environment and sick building syndrome}

Indoor work environment refers to ambient environmental conditions which include air temperature and movement, relative humidity, and respirable. Indoor work environment, 
particularly, indoor air quality, could negatively impact employee's physical health such as asthma exacerbation, respiratory allergies and complications [10]. In terms of monetary returns, improving indoor air quality is claimed to earn potential annual savings and productivity gains of at least 29 billion and could reduce absenteeism up to USD400 per employee [11]. Employees who are exposed to various types of particles and gaseous pollutants [12] [13] tend to increase their health risks which consequently affect their productivity and performance. Various studies have shown that indoor environment conditions increase the prevalence and risk factors of SBS regardless of types of building [14], air-conditioned rooms/buildings [12] and age of the buildings [15].

For example, Tarcan and Varol [16] in their study involving 375 individuals working in 25 hospitals found that indoor air quality is highly predictive of SBS and building general sufficiency level. Abdel-Hamid [3] found that poor ventilation and high temperature are predictive of SBS among office workers. Zamani et al. [17] claimed that increasing the ventilation rates, ventilation effectiveness and reducing indoor air pollutant could reduce SBS although risk factors of SBS were different between old and new building. Similarly, Bholah et al. [18] found that mechanical ventilators induce higher SBS symptoms compared to naturally ventilated buildings. Hidayah et al. [19], concurred when they found that ventilation and accumulation of possible contaminants within indoor environment exacerbates SBS symptoms. It is evident that majority of studies have been focusing on indoor air quality which justify its inclusion in this study. Based on these literatures, it is hypothesized that indoor work environment is significantly related with SBS.

\subsection{Indoor work environment and stress}

Theoretical underpinning on how indoor work environment influences stress could be traced back from the seminal work of Lazarus and Cohen [20], Evans [21] and a few others [22] on environmental stress. According to Evans, stress is a function of variation in environmental quality. Since environmental conditions are inevitable and enduring, the extent of their interferences with optimal human functioning and coping processes could lead to psychological discomfort. Lazarus and Cohen [20] categorized 'daily hassles' which refers to persons' irritating daily experience that are stable and repetitive as one of important stressors. Badayai [23] reasoned that working environment such as temperature, air and noise are stressprovoking stimuli that influence employees' psychological processes, produce negative affection, reduce motivation and social interaction. Thus, prolonged exposure to such environmental stressors would affect the stress level of the employees.

Rashid and Zimring [7], in their framework, suggested that indoor work environment may elicit stress "by the ways in which it affects individual and/or workplace needs.". For example, if an employee perceives that he/she need comfortable temperature to work, absence of such need would induce stress. In their review of the massive literature on the impact of indoor environment and stress in both office and healthcare setting, they further concluded that empirical supports on the direct linkage of indoor environment - stress is lacking and remains a knowledge gap. Woo and Postolache [24] argued that work environment is closely related to mood disorders especially for those who suffer seasonal affective disorder (SAD). SAD sufferers who are exposed to heat during summer might fall into depression cycle. In addition, hot temperature not only induces perspiration and dehydration but also increases toxicity risks from psychotropic medications used to treat mood disorders. In Malaysia, Makhbul [25] explored the effect of indoor air quality, lighting, acoustics, furniture and tools and building general environment on academician's emotional health and found that only building general environment and workplace ergonomics are significantly related with emotional health. Therefore, it is hypothesized that indoor work environment is significantly related to stress.

\subsection{Sick building syndrome and stress}

The dynamic interaction between SBS and stress is still unclear. Crawford and Bolas [26], in their review, contended that stress is correlated with SBS but cautioned the causal direction. They argued that whether stress is the predictor of SBS or vice versa is debatable as most studies are cross-sectional in nature. Ooi and Goh [27], on the other hand, reasoned that despite the substantial change of work environment for the past years, the SBS cases have not abated. Thus, it is logical to assume that SBS is induced by stress rather than the work environment. This is especially true when employees have to cope with increasing workload, a higher pace of work with less autonomy. In their survey involving 2160 employees, they found the prevalence of SBS among employees who reported high levels of physical and mental stress. As studies scrutinizing this direct causal effect are limited, this study postulates that SBS and stress is related where SBS is regarded as the risk factor of stress in line with the stress model.

\section{Methods}

This was a cross-sectional survey research using questionnaires as data collection method. Unlike the majority of previous studies which utilized actual measurement of indoor work environment such as temperature and humidity levels, this study used employees' responses to measure all the three constructs following the suggestion of Hedge and Erickson[28].

\subsection{Samples and procedure}

Five hundred ninety-eight employees from twenty companies participated in this study. Selection of employees in each company was based on random sampling procedure while the selection of companies used convenience sampling. Since research participation in not encouraging, the use of convenience sampling is seen as the best option. Participating companies were located in the state of Selangor and Johor, Malaysia. The majority of the 
respondents worked in manufacturing companies (74.7\%) while the rest worked in service-oriented companies. Male respondents were slightly higher at $51.8 \%$ compared to female $(48.2 \%)$ with the majority of respondents aged between 20 to 30 years old $(55 \%)$ followed by those aged $31-40$ years old $(32.1 \%), 41-50$ years old $(11.5 \%)$ and above 50 years old (1.3\%). Majority of respondents $(62.2 \%)$ had worked between $1-5$ years, $21.2 \%$ had worked $6-10$ years, $10.4 \%$ has worked $11-15$ years while the rest had worked more than 16 years. In terms of total hours of working, $65.9 \%$ had worked between 40-49 hours per week, $16.9 \%$ worked less than 39 hours per week, and 17.1\% worked more than 50 hours per week.

\subsection{Measures}

Adapted Cornell Office Environment Survey (short form) was used to measure Sick Building Syndrome ( 7 items) and Indoor Work Environment (7 items) [28]. Measurement of stress was developed based on the most common symptoms of occupational stress ( 7 items) which include insomnia, increase heart rate, lack of appetite, burnout, stomach ache, fatigue, and anxiety as shown in Table 1.

Table 1. Questionnaires items.

\begin{tabular}{|l|l|l|}
\hline Construct & Item & Description \\
\hline Indoor Wnvironment & B1 & Air temperature too cold \\
\cline { 2 - 3 } & B2 & Air temperature too warm \\
\cline { 2 - 3 } & B3 & Too little air movement \\
\cline { 2 - 3 } & B4 & Air too dry \\
\cline { 2 - 3 } & B5 & Unpleasant odour in air \\
\cline { 2 - 3 } Syndrome & B6 & Air too stale \\
\cline { 2 - 3 } & B7 & Air too dusty \\
\hline Suilding & C1 & Irritated, sore eyes \\
\cline { 2 - 3 } & C2 & Sore, irritated throat \\
\cline { 2 - 3 } & C3 & Hoarseness \\
\cline { 2 - 3 } & C4 & Stuffy, congested nose \\
\cline { 2 - 3 } & C5 & Excessive mental fatigue \\
\cline { 2 - 3 } & C6 & Headache across forehead \\
\cline { 2 - 3 } & C7 & Unusual tiredness, lethargy \\
\hline Stress & C8 & Insomnia \\
\cline { 2 - 3 } & C9 & Increase heart rate \\
\cline { 2 - 3 } & C10 & Lack of appetite \\
\cline { 2 - 3 } & C11 & Burnout \\
\cline { 2 - 3 } & C12 & Stomach-ache \\
\cline { 2 - 3 } & C13 & Fatigue \\
\cline { 2 - 3 } & C14 & Anxiety \\
\hline
\end{tabular}

Two items from were taken out from the analysis during the assessment of measurement model which was $\mathrm{C} 1$ for Indoor Work Environment and C7 from stress since their loading is below 0.5 following the suggestion by Hair et al. [29].

\subsection{Analysis}

PLS-SEM Version 2.0 [30] was used to analyze the data. SEM is a second-generation multivariate data analysis method that combines factor analysis and multiple regressions. Although there are two types of SEM which are covariance-based SEM (CB-SEM) and partial least square SEM (PLS-SEM), the use of PLS-SEM in this study was more appropriate since it is exploratory in nature [31]. The use of SEM enables model testing that is more robust compared to conventional regression modelling. Prior to examining the structural model for hypotheses testing, a measurement model was assessed to determine constructs' convergent and discriminant validity.

\section{Results}

Table 2. Items loadings and reliability.

\begin{tabular}{|c|c|c|c|c|c|c|c|}
\hline & $\begin{array}{l}\text { Item } \\
\text { s }\end{array}$ & $\begin{array}{l}\text { Load } \\
\text { ings }\end{array}$ & M & SD & AVE & $\mathrm{CR}^{*}$ & CA \\
\hline \multirow[t]{12}{*}{ IE } & & 0.72 & 2.60 & 1.10 & 0.56 & 0.88 & 0.84 \\
\hline & \multirow[t]{2}{*}{ B2 } & 4 & 0 & 5 & 9 & 7 & 7 \\
\hline & & 0.66 & 2.66 & 1.01 & & & \\
\hline & \multirow[t]{2}{*}{ B3 } & 2 & 9 & 9 & & & \\
\hline & & 0.71 & 2.77 & 0.99 & & & \\
\hline & \multirow[t]{2}{*}{ B4 } & 6 & 1 & 4 & & & \\
\hline & & 0.80 & 2.66 & 1.12 & & & \\
\hline & \multirow[t]{2}{*}{ B5 } & 2 & 4 & 3 & & & \\
\hline & & 0.83 & 2.57 & 1.15 & & & \\
\hline & \multirow[t]{2}{*}{ B6 } & 8 & 4 & 9 & & & \\
\hline & & 0.77 & 2.68 & 1.13 & & & \\
\hline & \multirow[t]{2}{*}{ B7 } & 1 & 6 & 5 & & & \\
\hline \multirow[t]{16}{*}{ SBS } & & 0.73 & 2.22 & 1.04 & 0.57 & 0.88 & 0.84 \\
\hline & \multirow[t]{2}{*}{$\mathrm{C} 1$} & 3 & 7 & 9 & 1 & 8 & 9 \\
\hline & & 0.80 & 2.32 & 1.01 & & & \\
\hline & \multirow[t]{2}{*}{$\mathrm{C} 2$} & 9 & 4 & 3 & & & \\
\hline & & 0.76 & 2.10 & 0.99 & & & \\
\hline & \multirow[t]{2}{*}{$\mathrm{C} 3$} & 8 & 5 & 4 & & & \\
\hline & & 0.76 & 2.55 & 1.12 & & & \\
\hline & \multirow[t]{2}{*}{$\mathrm{C} 4$} & 9 & 7 & 5 & & & \\
\hline & & 0.74 & 2.76 & 1.08 & & & \\
\hline & \multirow[t]{2}{*}{ C5 } & 2 & 3 & 2 & & & \\
\hline & & 0.70 & 2.51 & 1.08 & & & \\
\hline & \multirow[t]{2}{*}{ C6 } & 8 & 3 & 5 & & & \\
\hline & & 0.71 & 2.52 & 1.07 & & & \\
\hline & \multirow[t]{2}{*}{$\mathrm{C} 8$} & 1 & 8 & 3 & & & \\
\hline & & 0.74 & 2.64 & 1.06 & 0.58 & 0.90 & 0.87 \\
\hline & \multirow[t]{2}{*}{ C9 } & 4 & 7 & 1 & 0 & 6 & 9 \\
\hline ST & & 0.74 & 2.12 & 1.06 & & & \\
\hline \multirow[t]{9}{*}{$\mathbf{R}$} & \multirow[t]{2}{*}{$\mathrm{C} 10$} & 0 & 4 & 3 & & & \\
\hline & & 0.79 & 2.04 & 1.06 & & & \\
\hline & \multirow[t]{2}{*}{ C11 } & 8 & 2 & 7 & & & \\
\hline & & 0.75 & 1.99 & 1.09 & & & \\
\hline & \multirow[t]{2}{*}{$\mathrm{C} 12$} & 0 & 7 & 1 & & & \\
\hline & & 0.81 & 1.75 & 1.01 & & & \\
\hline & \multirow[t]{2}{*}{ C13 } & 1 & 3 & 0 & & & \\
\hline & & 0.77 & 2.00 & 1.10 & & & \\
\hline & $\mathrm{C} 14$ & 4 & 5 & 4 & & & \\
\hline
\end{tabular}

IE: Indoor Environment

SBS: Sick Building Syndrome

STR: Stress

Table 2 shows the mean, standard deviation (SD), composite reliability (CR), Cronbach Alpha, and AVE and loadings of each item for each construct. The measurement model shows that Indoor Environment, Sick Building Syndrome, and Stress had adequate reliability since the values of $\mathrm{CR}$ and $\mathrm{AC}$ were all above 0.7 [31]. Convergent validity of each construct was also sufficient as each factor loading and average variance extracted exceeded the recommended value of 0.5 [29]. Table 3 shows that the AVE value of each construct is also higher 
than the squared correlations between the latent variable and all other variables which indicate that discriminant validity is achieved [32].

Table 3. Discriminant validity.

\begin{tabular}{lccc}
\hline & \multicolumn{3}{c}{ Correlations } \\
& IE & SBS & STR \\
\hline Indoor Environment & $\mathbf{0 . 7 5 4}$ & & \\
Sick Building Syndrome & 0.435 & $\mathbf{0 . 7 5 6}$ & \\
Stress & 0.367 & 0.743 & $\mathbf{0 . 7 6 2}$ \\
\hline
\end{tabular}

Notes: * Calculated using Fornell and Larker's (1981) method Diagonals (in bold) represent the average variance extracted while other entries represent the squared correlations.

Table 4 and Fig. 1 show path coefficients of the structural model. The indoor work environment had a significant relationship with Sick Building Syndrome but not with Stress $(t<1.96)$. Moreover, SBS had a significant strong positive relationship with stress. To conclude, hypotheses 1 and 3 were accepted and hypothesis 2 was rejected.

Table 4. Path coefficient.

\begin{tabular}{lllll}
\hline Hypothesis & Relationship & $\begin{array}{l}\text { Std. } \\
\text { Beta }\end{array}$ & SE & t-value \\
\hline & & 0.43 & 0.03 & \\
H1 & IE -> SBS & 5 & 8 & $11.392^{* *}$ \\
& & 0.05 & 0.03 & \\
H2 & IE -> Stress & 5 & 4 & 1.606 \\
& & 0.71 & 0.02 & $28872.000^{*}$ \\
H3 & SBS -> Stress & 9 & 5 & $*$ \\
\hline
\end{tabular}

$* * \mathrm{p}<0.01$

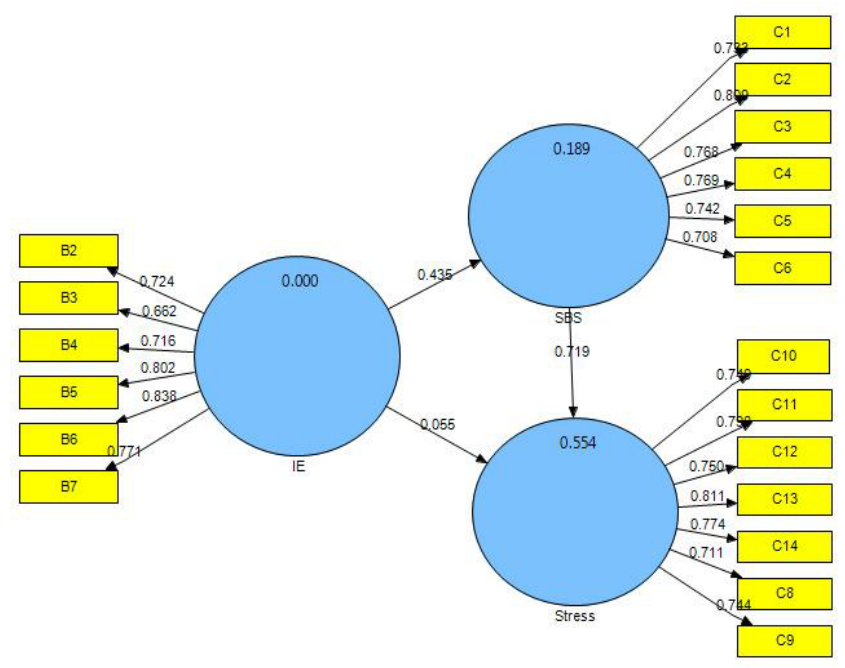

Figure 1. Path coefficient.

\section{Discussion and implications}

This study implies that further scrutiny is needed to investigate the dynamics of indoor work environment-SBSstress linkages. It is evident that indoor work environment is an important consideration to reduce SBS but not stress.
This finding contradicts with the theory of environmental stress [21], [22] where work environment has enduring features that influence whether or not stress is produced.. However, the strong relationship between SBS and stress demand further investigation. Perhaps, a concept of spill over could adequately explain the strong link of SBS and stress. When SBS become prevalent, it interferes or spill over to their physiological health. This explains the strong relationship of these two constructs. Future studies might need to dwell further on this interaction and provide a framework explaining their connection.

This study is not without limitation. As the nature of this study is cross-sectional, causality inference is cautioned. Furthermore, all measures are based on employees' perceptions rather than actual measurement of the indoor environment, SBS and stress. However, it is important to note that self-rating predicts better compared to objective measurement [33]. Furthermore, subjective measures are also more widely use and easy to assess.

Another limitation of this study is that it was conducted based on limited studies available and direct causal assumptions. Thus, future studies might investigate whether SBS mediates the relationship between indoor work environment and stress.

\section{References}

1. R. Runeson-Broberg and D. Norbäck, "Sick building syndrome (SBS) and sick house syndrome (SHS) in relation to psychosocial stress at work in the Swedish workforce," Int. Arch. Occup. Environ. Health, vol. 86, no. 8, pp. 915-922, 2013.

2. W. A. J. W. Yahaya, S. N. J. Ahmad, and M. Z. M. Zain, "Application of Persuasive Multimedia to Raise Stress Awareness among the Secondary School Students," IERI Procedia, vol. 3, pp. 105-113, 2012.

3. M. a Abdel-Hamid, S. A Hakim, E. E. Elokda, and N. S. Mostafa, "Prevalence and risk factors of sick building syndrome among office workers.," J. Egypt. Public Health Assoc., vol. 88, no. 2, pp. 109-14, 2013.

4. P. K. Wilke, W. H. Gmelch, and N. P. Lovrich, "Stress and productivity: Evidence of the inverted U function," Public Product. Rev., vol. 9, no. 4, pp. 342-356, 1985.

5. S. N. Kamaruzzaman, C. O. Egbu, E. M. A. Zawawi, S. B. A. Karim, and C. J. Woon, "Occupants satisfaction toward building environmental quality: structural equation modeling approach," Environ. Monit. Assess., vol. 187 , no. $5,2015$.

6. K. Fairbrother and J. Warn, "Workplace dimensions, stress and job satisfaction," J. Manag. Psychol., vol. 18, no. 1, pp. 8-21, 2003.

7. M. Rashid and C. Zimring, "A Review of the Empirical Literature on the Relationships Between Indoor Environment and Stress in Health Care and Office Settings," Environment and Behavior, vol. 40, no. 2. pp. 151-190, 2008.

8. Kazutaka Kogi, "Current Problems-Emerging Issues in Occupational and Environmental Health," Environ. Manag. Heal., vol. 8, no. 5, pp. 167-169, 1997.

9. J. A. Hole and M. Pande, "Worker productivity, occupational health, safety and environmental issues in 
thermal power plant," in Industrial Engineering and Engineering Management, 2009. IEEM 2009. IEEE International Conference on, 2009, pp. 1082-1086.

10. J. Sundell, "On the history of indoor air quality and health.," Indoor Air, vol. 14 Suppl 7, no. Suppl 7, pp. 51-58, 2004.

11. P. Wargocki, "Productivity and Health Effects of High Indoor Air Quality," in Encyclopedia of Environmental Health, 2011, pp. 688-693.

12. B. F. Yu, Z. B. Hu, M. Liu, H. L. Yang, Q. X. Kong, and Y. H. Liu, "Review of research on air-conditioning systems and indoor air quality control for human health," Int. J. Refrig., vol. 32, no. 1, pp. 3-20, 2009.

13. J. A. Bernstein, N. Alexis, H. Bacchus, I. L. Bernstein, P. Fritz, E. Horner, N. Li, S. Mason, A. Nel, J. Oullette, K. Reijula, T. Reponen, J. Seltzer, A. Smith, and S. M. Tarlo, "The health effects of non-industrial indoor air pollution.," J. Allergy Clin. Immunol., vol. 121, no. 3, pp. 585-91, 2008.

14. J. C. Vischer, "The Concept of Workplace and its values to Managers," Calif. Manage. Rev., vol. 49, no. 2, pp. 1-18, 2006.

15. K. Engvall, C. Norrby, J. Bandel, M. Hult, and D. Norback, "Development of a Multiple Regression Model to Identify Multi-Family Residential Buildings with a High Prevalence of Sick Building Syndrome (SBS)," Indoor Air, vol. 10, no. 2, pp. 101-110, 2000.

16. E. Tarcan, E. Sait Varol, and M. Ates, "A qualitative study of facilities and their environmental performance," Manag. Environ. Qual. An Int. J., vol. 15, no. 2, pp. 154-173, 2004.

17. M. E. Zamani, J. Jalaludin, and N. Shaharom, "Indoor air quality and prevalence of sick building syndrome among office workers in two different offices in selangor," Am. J. Appl. Sci., vol. 10, no. 10, pp. 11401147, 2013.

18. R. Bholah, I. Fagoonee, and A. H. Subratty, "Sick building syndrome in Mauritius: Are symptoms associated with the office environment?," Indoor Built Environ., vol. 9, no. 1, pp. 44-51, 2000.

19. A. Norhidayah, L. Chia-Kuang, M. K. Azhar, and S. Nurulwahida, "Indoor Air Quality and Sick Building Syndrome in Three Selected Buildings," Procedia Eng., vol. 53, no. 2010, pp. 93-98, 2013.

20. R. S. Lazarus and J. B. Cohen, "Environmental Stress," in Human Behavior and the Environment: Current Theory and Research, I. Altman and J. F. Wohlwill, Eds. New York: Spectrum, 1977, pp. 89-127.
21. G. W. Evans, Environmental Stress. Cambridge: Cambridge University Press, 1984.

22. S. Cohen, Gary W. Evans, D. Stokols, and D. S. Krantz, Behavior, Health, and Environmental Stress. New York: Springer, 1986.

23. A. R. A. Badayai, "A Theoretical Framework and Analytical Discussion on Uncongenial Physical Workplace Environment and Job Performance among Workers in Industrial Sectors," Procedia - Soc. Behav. Sci., vol. 42, no. July 2010, pp. 486-495, 2012.

24. J. Woo and T. T. Postolache, "The impact of work environment on mood disorders and suicide: Evidence and implications," Int. J. Disabil. Hum. Dev., vol. 7, no. 2, pp. 185-200, 2008.

25. Z. M. Makhbul, "Workplace Environment Towards Emotional Health," Int. J. Acad. Res. Bus. Soc. Sci., vol. 3, no. 1, pp. 183-195, 2013.

26. J. O. Crawford and S. M. Bolas, "Sick building syndrome, work factors and occupational stress," Scand. J. Work. Environ. Heal., vol. 22, no. 4, pp. 243-250, 1996.

27. P. L. Ooi and K. T. Goh, "Sick building syndrome: An emerging stress-related disorder?," Int. J. Epidemiol., vol. 26, no. 6, pp. 1243-1249, 1997.

28. A. Hedge and W. A. Erickson, "A Study of Indoor Environment and Sick Building Syndrome Complaints in Air-Conditioned Offices: Bencahmarks for Facility Performance," Int. J. Facil. Manag., vol. 1, no. 4, pp. 185-192, 1997.

29. J. F. H. Jr, W. C. Black, B. J. Babin, and R. E. Anderson, Multivariate Data Analysis, 7th ed. 2006.

30. C. M. Ringle, S. Wende, and A. Will, "SmartPLS 2.0.M3.," Hamburg: SmartPLS, http://www.smartpls.de., 2005. .

31. J. F. Hair, M. Sarstedt, T. M. Pieper, and C. M. Ringle, "The Use of Partial Least Squares Structural Equation Modeling in Strategic Management Research: A Review of Past Practices and Recommendations for Future Applications," Long Range Plann., vol. 45, no. 5-6, pp. 320-340, 2012.

32. J. Henseler, C. M. Ringle, and M. Sarstedt, "A new criterion for assessing discriminant validity in variancebased structural equation modeling," J. Acad. Mark. Sci., 2014.

33. S. Cohen, T. Kamarck, and R. Mermelstein, "A Global Measure of Perceived Stress," vol. 4. 